\title{
EDITORIAL
}

\section{White Privilege in Health Care: Following Recognition With Action}

\author{
Joseph Hobbs, MD \\ Department of Family Medicine, Medical College of Georgia at Augusta University, Augusta, Georgia \\ Ann Fam Med 2018;16:197-198. https://doi.org/10.1370/afm.2243.
}

I have observed the implications of white privilege from the standpoint of one who does not possess it. This experience leads me to believe that the essay "White Privilege in a White Coat: How Racism Shaped My Medical Education"1 describes one of many places to start on the path of self-realization and active interventions to address the racial disparities in health care and society as a whole.

\section{WHAT IS WHITE PRIVILEGE?}

White privilege is a long-standing debated concept defining a set of privileges available to white people because of their race and unavailable to others. The concept is integrally related to realized or unrealized personal or institutional racism. White privilege has been the subject of increased public discussion over the last 3 decades. Peggy McIntosh's influential 1989 essay, "White Privilege: Unpacking the Invisible Knapsack $^{\prime 2}$ describes a white person's discovery of personal privileges in everyday life, afforded specifically by race, that contribute to a racial privilege gap and to racism. This racial privilege is described as "unearned" and seems cloaked in invisibility. According to McIntosh, this depersonalization of white privileges, using such words as "invisible" and "unearned" (or similar current terms such as "unconscious," "implied," "inadvertent," or "institutional"), collectively obscures recognition of the painful impact of racism and diminishes personal responsibility and the belief that one should or can change their perceptions of racial privilege.

Conflicts of interest: autbor reports none.

\section{CORRESPONDING AUTHOR}

Joseph Hobbs, MD

Department of Family Medicine

Medical College of Georgia at Augusta University

1120 15th Street, HB-4012

Augusta, GA 30912

jhobbs@augusta.edu
The concepts of white privilege and unconscious and implicit racial bias dilute personal responsibility for racism because the individual's personal involvement may not be realized or intended. In the case of institutional racism, the institution may promote the collective and not the individual. Since one may not have control of an institution, the mere recognition of institutional racism will not necessarily effect the changes required to mitigate the source of racial inequality and inequity. In fact, the institution can become an inanimate structure against which blame can be cast while avoiding personal complicity for its negative attributes. The same could be said for Peggy McIntosh's "invisible knapsack." Its invisibility allows people to avoid personal responsibility for racism, although its contents are likely visible to those without this privilege.

\section{EFFECTS OF WHITE PRIVILEGE}

To understand the negative implications of white privilege requires a broader understanding of its effect on those who do not possess it. Many nonwhite individuals have had negative personal experiences in social systems where racism was supported by law or custom and their progeny continue to be affected by this painful legacy. For example, a nonwhite person who experiences racial profiling is more deeply affected than is a white person who assumes he is not likely to be stopped by the police because of race. When a white person performs better than colleagues knowing that the likelihood of rewards will be greater than those of other races, and that is compared with a nonwhite person who performs just as well knowing that rewards are not as certain or may not occur because of their race, it is a much more ominous personal experience.

\section{HEALTH CARE AND RACE}

Although the white privilege debate is complicated by disparities in privileges based on other characteristics (eg, economics and educational status), ample evidence 
suggests a disparity in the quality of health care delivered to whites and nonwhites. According to a 2003 Institute of Medicine report, this disparity cannot be accounted for by clinical appropriateness, needs, and patient preferences, but rather exists at the level of the system of health care as well as by discrimination that occurs at personal, institutional, and societal levels. ${ }^{4}$ This disparity is an example of the assets of white privilege. Differences in life expectancy and health outcomes based on race likely elicit greater personal concerns for an individual whose race confers a lower life expectancy. ${ }^{3}$

The constellation of personal and institutional privilege and power in health care settings provides opportunities to either sustain racial health care privilege gaps or transform these organizations and those who work within them to effectively reduce health care quality disparities between minority and non-minority persons. ${ }^{5}$ Although tasked with serving all people, while leadership positions in the health care system are occupied mostly by individuals of privilege-based on multiple characteristics including race-the system has the tendency to project values and provide services that meet the needs of the majority while not fully recognizing the needs of the minority. Recognizing white privilege's impact on personal and institutional engagement in patient care, education, and research in the health care workplace is the initial step, but should occur concurrently with active personal and institutional efforts to diminish racially based privilege gaps or disparities in the quality of health care and all of the other components that constitute this service.

\section{RECOGNITION AND ACTION}

There may be a personal emotional relief when one comes to grips with issues such as implicit and unconscious racial bias and white privilege, but this relief is ineffective if not reflected in actions. Actions should attempt to not only mitigate personal racism and racial insensitivities, but be the catalyst to address the impact of this privilege gap in settings where we work, learn, live, play, and worship. Failure to follow recognition with action in the personal exploration of concepts such as white privilege can inadvertently support assumptions that these advantages are only cast upon you and not in some part of your own making.

In health care, racist comments and racial insensitivity, racially biased decisions, and stereotyping continue to occur in patient care settings, personnel recruitment and management, and school admissions. Those of us who experienced this firsthand in the early 1970s, as well as the racial bias and stereotyping described in this issue's essay, hoped that this level of racism would not be evident today. Similar experiences, however, continue to be documented. ${ }^{6}$

To experience implicit or unconscious bias in the professional and personal settings of health care and fail to address it is a missed opportunity to facilitate change. Personal introspection and understanding of the negative impact of white privilege without taking action begs the question, why? Is lack of action in the face of racial bias due to disbelief, fear, indifference, conformity to social norms, or unresolved personal racism? If reasons fall into any of these categories, then one needs to continue unpacking that knapsack.

To read or post commentaries in response to this article, see it online at http://www.AnnFamMed.org/content/16/3/197.

Submitted March 7, 2018; submitted, revised, March 23, 2018; accepted March 27, 2018.

Key words: racism; racial bias; racial discrimination; racial prejudice; institutional racism; unconscious bias

\section{References}

1. Romano MJ. White privilege in a white coat: how racism shaped my medical education. Ann Fam Med. 2018;16(3):261-263.

2. Mclntosh, P. White privilege: unpacking the invisible knapsack. Peace and Freedom Magazine. 1989. July/August:10-12.

3. Ayanian JZ. The costs of racial disparities in health care. Harvard Business Review. 2015:93(10). https://hbr.org/2015/10/the-costs-ofracial-disparities-in-health-care. Published Oct 1, 2015.

4. Institute of Medicine. Unequal Treatment: Confronting Racial and Ethnic Disparities in Health Care. Washington, DC: The National Academies Press; 2003.

5. Association of American Medical Colleges. Addressing racial disparities in health care: a targeted action plan for academic medical centers. https://members.aamc.org/eweb/upload/Addressing $\% 20$ Racial\%20Disparaties.pdf. Published 2009.

6. Tweedy D. Black Man in a White Coat: A Doctor's Reflections on Race and Medicine. New York, NY: Picador; 2015. 